\title{
Modelling of Home Appliances Using Fuzzy Controller in Achieving Energy Consumption and Cost Reduction
}

\author{
Khadija Parvin $^{1}$, Ali Q. Al-Shetwi ${ }^{2,}$ ", M. A. Hannan ${ }^{1}$, Ker Pin Jern ${ }^{1}$ \\ ${ }^{I}$ Department of Electrical Power Engineering, Universiti Tenaga Nasional, \\ 43000 Kajang, Selangor, Malaysia \\ ${ }^{2}$ Electrical Engineering Department, Fahad Bin Sultan University, \\ 71454 Tabuk, Saudi Arabia \\ aalshetwi@fbsu.edu.sa
}

\begin{abstract}
While home energy prices keep rising, homeowners nowadays are searching for the right options to reduce their electricity bills. Besides, the increase in power consumption can contribute to environmental pollution. Therefore, the proper management of energy in the domestic sector is a vital element for creating a sustainable environment and cost reduction. In this study, the most domestic household appliances consumption of energy are modelled and analysed using the fuzzy logic controller (FLC) in order to permit the home energy management system (HEMS) to perform energy utilization estimation and cost analysis. These appliances are the heating ventilation and air conditioning (HVAC), electric water heater (EWH), and lighting, respectively. The developed system can help to analyse the appliances' energy consumption and cost sceneries during peak and off-peak hours. The modelling of a fuzzy-based domestic appliances controller for HEMS takes the peak and non-peak tariff of Malaysian grid into consideration. The simulation results demonstrate that the developed models are able to manage energy consumption and cost reduction efficiently. By using the proposed FLC, the cost of energy is reduced by $21.75 \%, 30.77 \%$, and $41.96 \%$ for the HVAC, EWH, and dimmable lamps, respectively. In sum, the FLC shows good performance to reduce the cost and power consumption toward efficient HEMS.
\end{abstract}

Index Terms-Home energy management; The cost of energy; Fuzzy logic controller; HVAC system; Home appliances; Building energy.

\section{INTRODUCTION}

The power demands are going to rise so significantly even more in the future. This phenomenon influences the researchers to focus on numerous studies in order to provide a superior solution for power conservation. For different decades, energy emergency and environmental issues have attracted incredible attention regarding power savings and power utilization efficiency. The peak demand in the real estate sector has risen in recent years and made undesirable impacts on the unwavering quality and dependability of intensity frameworks. The total energy demand is estimated to increase by $75 \%$ at the end of 2020 compared to 2000 [1]. Moreover, in the next several decades, the domestic area

Manuscript received 1 July, 2020; accepted 3 February, 2021.

This research was supported by the Ministry of Higher Education of Malaysia under Grant No. 20190101LRGS. is expected to expand to $30 \%-40 \%$ of the total energy utilization everywhere throughout the world [2].

A building energy management system (BEMS) is getting significant attention because of concerns related to global warming and power storage, especially in domestic areas. In this regard, the home energy management system (HEMS) framework helps decline the demand for power, particularly at peak load periods [3]. HEMS not only should allow for the automated control of energy at home, but also should be used as a way to combat climate change [4]. Different efforts, which incorporate the control of different home appliances (i.e., water heater, heating ventilation air conditioning (HVAC), coolers, electric vehicles, lighting, and others), have been applied to build up various HEMS frameworks. In residential homes, HEMS can be implemented to help manage the energy supply by interacting with building loads and utilities, controlling power consumption, and get data, (e.g., traffic costs) to minimize power utilization by scheduling the use of building appliances [5]. HEMS innovations can give a common fulfilment between consumers by understanding their comfort inclinations and the utility by helping energy sparing techniques [6]. The smart home is one of the ways of utilization of smart innovations in domestic buildings that can give chances to improved energy management, decreased energy consumption, energy-saving, reduced greenhouse gas emission, and improved home automation. Energy utilization in a domestic building depends on numerous factors, including the number of inhabitants living in the building, people at home awake, and electrical appliance power [7].

Demand response (DR) ought to be an integrative and essential feature of the next smart grid in the residential electricity industry, with the introduction of smart building loads and appliances. By empowering DR with intelligent loads, residential consumers are offered an effective and competitive approach to coping with their usage of power for decreasing energy costs and increasing customer satisfaction, who is also ready to take an interest in demandside management and load saving [8]. To accomplish the points of interest and completely build up the DR potential in the residential part, a smart BEMS plays a key role, and 
so has recently gained a lot of attention. As far as residential loads, not every one of them could perform DR automated, and some of them semi-automated operated [9]. There are automated DRs, e.g., the electric water heater (EWH), heating ventilation air conditioning (HVAC), garments dryer (CD), and electric vehicles (EV). The completely automated appliances could be observed and constrained by the HEMS, which is responsible for checking and optimizing the power utilization of residential apparatuses. The HEMS can gather continuous and anticipated data about outdoor/indoor temperatures, power costs, and high temperature water utilization, so it can adjust the power utilization dependent on the accessible data [10].

Recently, extensive publications take into account the properties of the household or domestic home energy management system using artificial intelligence techniques and optimization methods. For instance, Chen et al. [11] present the model predictive control (MPC)-based load scheduling technique for the residential HEMS pretending time-differing retail evaluating set up. The study focused on smart scheduling of the thermal appliances in the buildings in tandem with thermal mass storage to protect against rising costs and take advantage of low demand time spans. In another study [12], MPC was used to schedule the home appliance based on the price of energy from renewable sources. However, accurate evaluating of the domestic appliances-based grid feeding was not discussed. In [13], the particle swarm optimization (PSO) was used for building control to attain a convenient building environment with high energy efficiency. Optimization of the visual comfort and energy consumption of the building's light by PSO is also presented by authors in [14]. However, the PSO in both studies is not used to control the consumption based on peak demand or cost-saving. Zhang et al. in [15] discussed a machine learning system design to learn the energy consumption model of HVACs, integrate the learning mechanism with optimization methods to create optimum demand response policies and data structure design to store and capture current and home energy management systems. Although the results showed a reduction in the energy consumed by HVAC, the other appliances were not taken into consideration. The photovoltaic (PV) roofing system is integrated with the system to show the cost-effectiveness of the appliances [16]. However, this study focused on feeding scheduling between the grid and the PV to guarantee the cost reduction.

FLC has also been utilized in the literature for HEMS to control building electricity. FLC is simple to execute, and based on linguistic rules it can handle linear and non-linear systems; besides, it requires no mathematical model [17]. It was developed to obtain the optimum temperature scheduling for air-conditioning in order to the day-ahead outdoor temperature forecasts and electricity price [18]. The results of this study proved the ability to FLC to reduce the energy cost while comfort is still retained. DR is applied by HEMS in a smart building environment using FLC. The simulation results showed the capacity of FLC in minimizing power consumption and scheduling the activity of air conditioning units. Load scheduling applying FLC in the smart building is used in [19]. The researcher utilized fuzzy procedures to demonstrate consumer comfort and forecast prices to reduce comfort levels and decrease power consumption in a building. A high-goal model of energy utilization for any building using fuzzy logic inference system is also introduced in [20]. Rajeswari and Janet [21] presented load scheduling in a home energy management system using fuzzy logic to reduce the power consumption, and thereby decrease the cost. Based on the accessible energy, the load can be turned ON or OFF around then without influencing the comfort of the customers. The proposed method is developed based on the customer's perspective to minimize the energy cost and maintaining the consumer's comfort while the cost reduction was minimum. FLC has been presented for heating and cooling [22], as well as for to decrease power consumption [23] of the buildings. In most cases, FLC is utilized in temperature and machine control because of its capability to provide a quick response and increase model stability and reliability as proved in [24], [25]. The fuzzy logic controller is also appointed to decrease power consumption and cost of both HVAC and illumination management systems. Simulation results have shown a significant decrease in the peak to average ratio (PAR), monetary cost, and power consumption [26]. Bissey et al. [27] presented the fuzzy logic systems to effectively optimize energy consumption in individual housing. The purpose of the study was to analyse the power consumption of the home appliances and decrease the energy consumption during the peak hours to prevent the need to extend the grid and thus save considerable costs However, the cost reduction was very small and the off-peak period was not taken into consideration. Moreover, the modulation of home appliances using the fuzzy controller to reduce the electricity consumption and cost-based on-peak and off-peak periods is not sufficiently covered in the literature, especially for an environment like Malaysia. It is worth mentioning that this study is compared with the aforementioned articles. It became clear that the energy consumption and monetary cost witness more reduction when customers' preferences are considered and the customers are given greater flexibility to operate their appliances, as well as to increase their own comfort level too.

Although most of the recent studies discussed above focused on the scheduling of the appliance, scheduling between grid and renewable sources to decrease the cost based on the availability, DR, modification of the appliance characteristics, and suggested new standards to reduce the energy consumption and cost for different countries, developing a domestic household appliances model for home energy management system in Malaysia based on the national grid tariff is not sufficiently covered. Besides, the work referred above does not discuss the cost reduction analysis of each appliance separately. Thus, this paper presents the design and modelling of a fuzzy-based domestic appliances' controller for HEMS taken the tariff and peak demand of Malaysian grid into consideration. Three domestic loads are simulated in Simulink/Matlab that include heating ventilation and air conditioning (HVAC), electric water heater (EWH), and dimmable lamp. The main aim of this paper is to develop a model that permits the HEMS to perform energy utilization estimation and cost analysis of various sorts of appliances based on with and 
without a controller. The designed model can help to analyse the energy consumption and cost sceneries during peak and off-peak hours. However, the noteworthy contribution is the development of an optimal Building Energy Management System of several kinds of domestic loads by using FLC controller. FLC controller is considered as a novel technique used for determining the optimum schedules of the building appliances in the intelligent HEMS to reduce the power consumption and energy cost in the domestic house. In this research, MFs of the fuzzy controller have optimized the output, which provides better results. FLC proves the superiority algorithm and ensures better performance compared to the other algorithms, and without FLC controller.

\section{HOME APPliAnCE MODELS}

In general, the most domestic household appliances consumption of energy are the HVAC, water heating, PCs, as well as TVs, and lighting (see Fig. 1). Therefore, this study focused on modelling and analysing the HVAC, water heating, and lighting. The most usual building appliances of a residential environment are demonstrated and constrained by utilizing Simulink and seascape instruments. Comment: Other household appliances can be modelled based on user necessities and device characteristics.

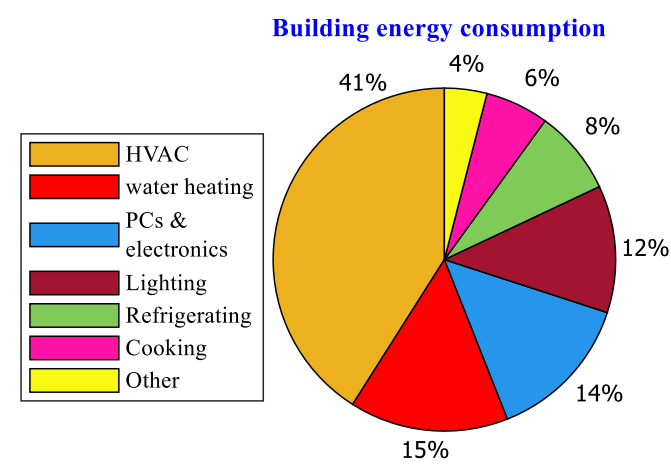

Fig. 1. Energy consumption based on appliances type.

\section{A. Heating Ventilation and Air Conditioning Modelling}

HVAC system is widely utilized in large buildings, particularly in the residential, industrial, and commercial areas to control the environment of the rooms or offices. The environmental factors controlled may, e.g., involve temperature, air-flow, and humidity. The ideal set-point of the environmental variables will rely upon the proposed utilization of the HVAC system. It is essential to discover ideal working purposes of HVAC frameworks to minimize power utilization, which is dependent on certain limitations, e.g., provide thermal comfort in the spaces. Power utilization optimization is usually based on two stages: an optimal working point to maximize power consumption under such constraints and a mathematical model between the output and input variables of the HVAC system. Commonly, these devices are made out of outer and inner units associated with pipelines in which a refrigerant flows. They have two status, including ON/OFF based on the driven inverter. In the first type, a thermostat regulates the key on/off of the compressor voltage source to maintain the air temperature at the optimum level. On the contrary, in the second form, the inverter drives the compressor in proportion to the variation between both the measured temperature and the set-point value. An explanation to ensure better results for energy consumption minimization from the second type of HVAC system is introduced in this section. Overall, there have been three forms of submodelling for modelling a single subsystem component of the entire HVAC model, including heating and cooling model, thermodynamic model, and cost energy model.

\section{Heating and cooling model}

More particularly, the simple cooling and heating subsystem component of the HVAC model is represented by (1). In this regard, the thermal power $\left(P_{t}\right)$ is corresponding to $(\Delta T)$ that represents the contrast between the measured and desired temperatures. Therefore, the technical maximum value of a saturation block imposes is expressed as follows

$$
\frac{d Q_{t}(t)}{d t}=\left\{\begin{array}{cc}
K \Delta T, & \text { if } 0<K \Delta T<P_{t, \max }, \\
0, & \text { otherwise, }
\end{array}\right.
$$

where $K$ is the related value that involves the coefficient of heat transfer and the surface area. Therefore, based on thermal power, an electric power $\mathrm{P}_{\mathrm{e}}(\mathrm{t})$ could be computed as per the equation below

$$
\mathrm{P}_{\mathrm{e}}(\mathrm{t})=\frac{\frac{\mathrm{dQ}_{\mathrm{t}}(\mathrm{t})}{\mathrm{dt}}}{\gamma}
$$

where $\gamma$ denotes the coefficient performance $(C O P)$ for the heating system, while in case of a cooling system, it represents the energy efficiency ratio (EER).

\section{- Thermodynamic model}

Building thermodynamic is a subsystem that measures the variations between indoor and outdoor temperature. It takes care of the heat losses to the environment and heat flow from the heater. The necessary variables and parameters of the building model are introduced: $\mathrm{T}_{\text {in }}(\mathrm{t})\left[{ }^{\circ} \mathrm{C}\right]$, indoor air temperature; $\mathrm{T}_{\mathrm{in}, \mathrm{set}}(\mathrm{t})\left[{ }^{\circ} \mathrm{C}\right]$ - set-point indoor air temperature; $\mathrm{T}_{\text {out }}(\mathrm{t})\left[{ }^{\circ} \mathrm{C}\right]$ - outdoor air temperature; $R_{t h}\left[\frac{\mathrm{m}^{2} *{ }^{\circ} \mathrm{C}}{W}\right]$ equivalent thermal resistance of the space; Mair $[\mathrm{Kg}]$ - air mass inside the room; $c\left[\frac{J}{\mathrm{~kg} * \mathrm{k}}\right]$ - the heat capacity of air at constant pressure; $c\left[\frac{J}{\mathrm{~kg} * \mathrm{k}}\right]$ - thermal power; $\frac{d Q_{t}(t)}{d t}$ thermal loss power. Equation (3) describes the impact on the change of indoor temperature and the lack of heat due to the outside climate

$$
\frac{d Q_{\text {loss }}(t)}{d t}=\frac{T_{\text {in }}(t)-T_{\text {out }}(t)}{R_{\text {th }}}
$$

Equation (4) and equation (5) represent the change of the indoor temperature, taking into account the heat transfer by the HVAC system and the lack of heat by the outside 
temperature for cooling and heating, respectively:

$$
\begin{aligned}
& \frac{d Q_{\text {in }}(t)}{d t}=\frac{1}{M_{\text {air }} * c}\left(\frac{d Q_{t}(t)}{d t}-\frac{d Q_{\text {loss }}(t)}{d t}\right), \text { Cooling system, } \\
& \frac{d Q_{\text {in }}(t)}{d t}=\frac{1}{M_{\text {air }} * c}\left(\frac{d Q_{t}(t)}{d t}+\frac{d Q_{\text {loss }}(t)}{d t}\right), \text { Heating system. }
\end{aligned}
$$

\section{- Cost energy model}

In this design, the "cost calculator" is a Gain block. In order to analyse the cost of energy, the cost meter incorporates the heat flow over time and multiplies it by the peak and off-peak periods of energy cost. In this regard, the equation of HVAC energy cost is expressed as follows

$$
\begin{gathered}
\operatorname{Cos} t=C_{p} \int_{T_{\text {start }}}^{T_{\text {end }}} P(t) d t+C_{o p} \int_{0}^{T_{\text {start }}} P(t) d t+ \\
+C_{o p} \int_{T_{\text {end }}}^{T_{h}} P(t) d t
\end{gathered}
$$

where $C_{\mathrm{p}}[\mathrm{RM} / \mathrm{kWh}]$ denotes the peak period within the energy cost $\left(\mathrm{T}_{\text {start }}, \mathrm{T}_{\text {end }}\right) ; \mathrm{C}_{\mathrm{op}}[\mathrm{RM} / \mathrm{kWh}]$ represents the offpeak period within the energy cost $\left(\mathrm{T}_{\text {start }}, \mathrm{T}_{\text {end }}\right)$; and $\mathrm{T}_{\mathrm{h}}$ is the time horizon, which determines the cost of energy. Based on (1)-(6), the HVAC model is designed in this study using the Matlab/Simulink environment, as illustrated in Fig. 2.

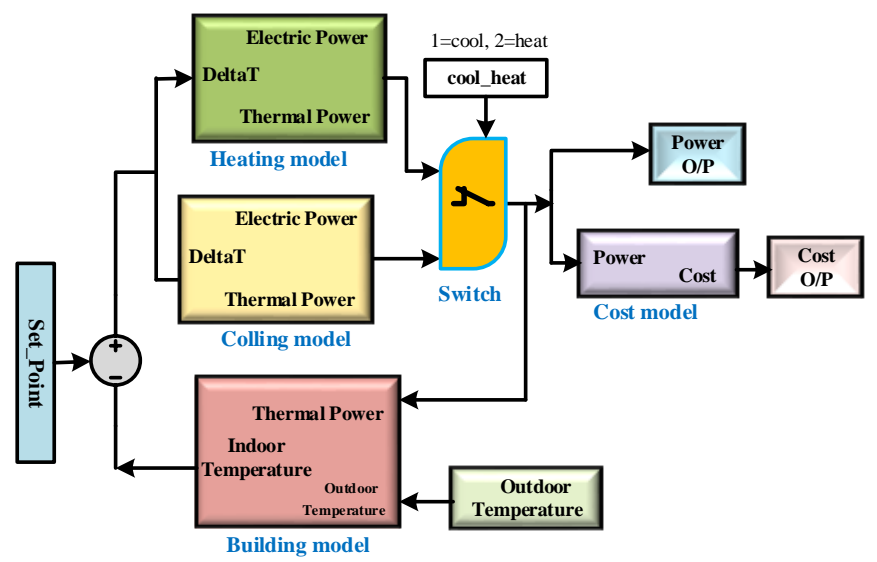

Fig. 2. Simulink model of the HVAC system.

\section{B. Domestic Electric Water Heater Modelling}

The second domestic loads modelled and controlled in this study are the electric water heaters $(\mathrm{EWH})$. EWHs are some of the most noticeable energy-intensive devices in domestic areas [28]. The electrical water heater uses energy depending on the amount of hot water used by people. Domestic EWH model is modelled to show how the water temperature in a water heater may change because of the electric resistance and warms up the water heater. Figure 3 illustrates a schematic representation of the water heater model in which $T_{a v g}$ is the average water temperature, $T_{a m b}$ is the ambient water temperature, $C_{w}$ is the thermal capacitance, and $R$ is the resistance of the water heater.

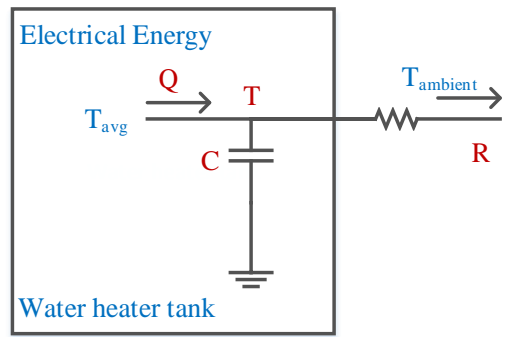

Fig. 3. Simple electric water heater model.

By considering the heat transfer in a single element domestic electric water heaters (DEWH) as shown in Fig. 4, the energy flow differential equation describing the temperature of DEWH can be expressed as follows

$$
C T(t)=G\left(T_{a}-T_{H}(t)\right)+H W_{d}(t)\left(T_{i n}-T_{H}(t)\right)+Q_{t}(t),
$$

where $C=\rho C p V, G=S A / R t h, H=\rho C p$. Besides, the heat loss in the tank is represented by $G\left(T_{a}-T_{H}(t)\right)$, and $H W_{d}(t)\left(T_{i n}-T_{H}(t)\right)$ represents the heat lost. The fundamental factors of the DEWH model are as follows: $\mathrm{C}\left[\mathrm{J} /{ }^{\circ} \mathrm{C}\right]$ - the thermal capacity of water in the tank; $\mathrm{T}_{\mathrm{H}}$ (t) $\left[{ }^{\circ} \mathbf{C}\right]$ - the temperature of the hot water tank; $\mathrm{T}_{\mathrm{a}}\left[{ }^{\circ} \mathbf{C}\right]-$ the temperature of the ambient air outside the tank; $\mathrm{T}_{\text {in }}\left[{ }^{\circ} \mathbf{C}\right]$ cold water inlet temperature; $\mathrm{W}_{\mathrm{d}(\mathrm{t})}[1 / \mathrm{sec}]$ - inlet cold water temperature; $\rho[\mathrm{kg} / \mathrm{J}]$ - the water density; $\mathrm{V}[\mathrm{l}]$ - tank volume; $C_{p}\left[\frac{J}{\mathrm{~kg} *^{\circ} \mathrm{C}}\right]$ - specific water heat; $\mathrm{SA}\left[\mathrm{m}^{2}\right]$ - the tank surface area, $R_{t h}\left[\frac{\mathrm{m}^{2} *^{\circ} \mathrm{C}}{W}\right]$ is the tank thermal resistance; and $Q(t)[W]$ represents the rate of energy input.

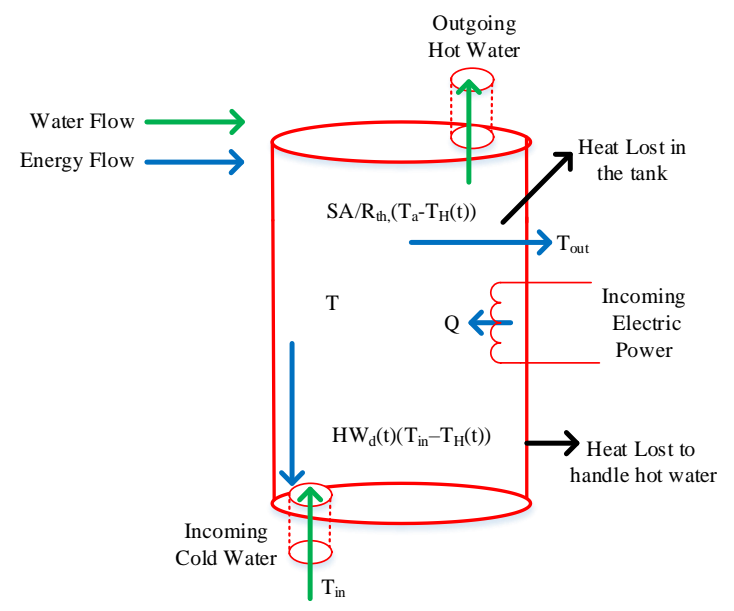

Fig. 4. Heat transfer in a single element DEWH. 
Figure 5 illustrates the thermostat used to control the temperature of a single element EWH. In this design, the thermostat will take the action in order to control the on/off status of the power source to keep the desired temperature and can be manually set up to the set-point of water heater temperature. The incoming electric power $(P(t))$ is represented according to the equation of the water heater as expressed in (8) as follows

$$
P(t)=\left\{\begin{array}{l}
1 \quad T_{e w h, t} \leq T_{\text {set }, t}-\Delta T \\
0 \quad T_{e w h, t} \geq T_{\text {set }, t}-\Delta T \\
P(t-\Delta t) \quad \text { otherwise }
\end{array}\right.
$$

where $T_{\text {ewh,t }}$, is the temperature of water; $T_{\text {set, }}$ is the set-point temperature; and $\Delta T$ is the dead-band of the water heater temperature $\left( \pm 2{ }^{\circ} \mathrm{C}\right)$.

The strategy depends on that in case the water tank temperature is lower than the set-point temperature, then the incoming power will be equal to the nominal power (i.e., the WH coils are switch $\mathrm{ON}$ ). On the other hand, the WH heat coils will be switched OFF if the temperature of the water tank is greater than the set-point temperature.

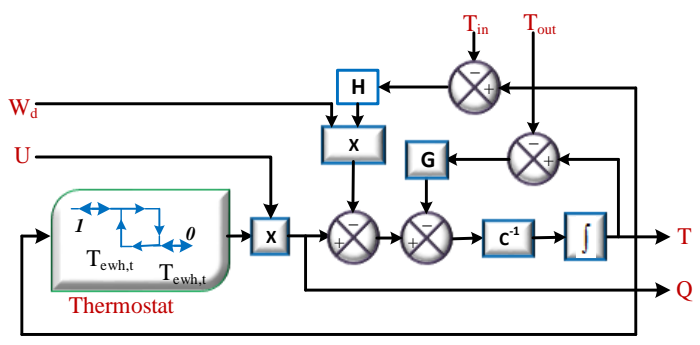

Fig. 5. A dynamic model of a thermostatically controlled DEWH.

The amount of power used in Watt by the EWH relies on the thermostat that operates and runs in the OFF/ON states. At a certain time, the power of EWH is determined using the following equation

$$
Q(t)=P(t) * u(t)
$$

where $P(t)$ is the status of the device rated power. Thus, in case $P(t)=1$, that means the device is switched on. On the other hand, if the $P(t)=0$, that means the device is switched off. Given constant values of $C, G, H, T_{i n}$, and $T_{\text {out }}$ and assuming $W D(\mathrm{t})$ and $Q(\mathrm{t})$ are piecewise constants over the time interval $t \in\left[\mathrm{t}_{\mathrm{o}}, \mathrm{t}_{\mathrm{f}}\right]$, then (7) can be re-expressed as follows

$$
\begin{gathered}
T(t)=T_{H}\left(t_{o}\right) e^{-\left(\frac{1}{R C}\right)\left(t-t_{o}\right)}+ \\
+\left(R G T_{a}+R B T_{i n}+R Q\right) *\left[1-e^{-\left(\frac{1}{R C}\right)\left(t-t_{o}\right)}\right]= \\
=T_{H}\left(t_{o}\right) e^{-\left(\frac{\left(t-t_{o}\right)}{\tau}\right)}+K\left[1-e^{-\left(\frac{\left(t-t_{o}\right)}{\tau}\right)}\right],
\end{gathered}
$$

where $R=\frac{1}{G+B}, \quad K=\frac{G T_{a}+G T_{i n}+Q}{G+B}, \quad \tau=\frac{C}{G+B}$, and
$\tau=R C$.

In sum, based on (7)-(10), the EWH model is developed in this study using the Matlab/Simulink environment as illustrated in Fig. 6.

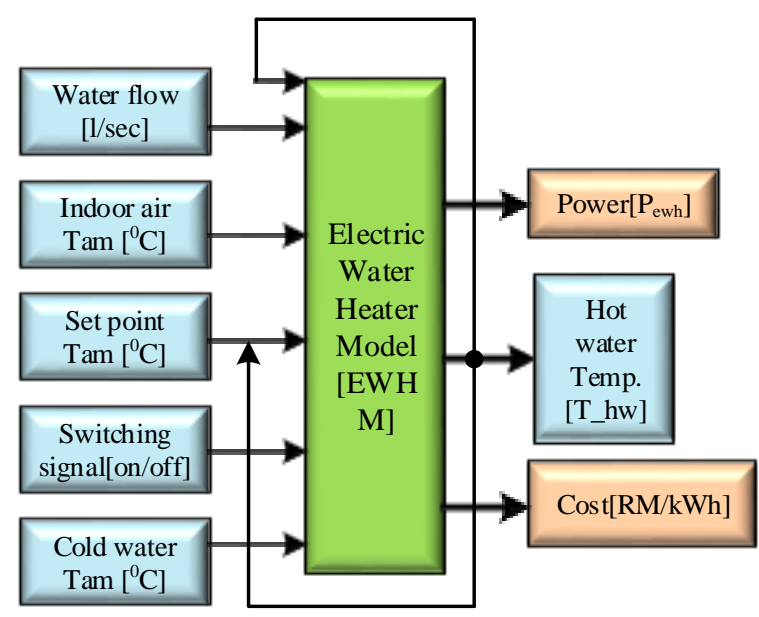

Fig. 6. Simulink model of the EWH system.

\section{Modelling of the Light}

The lighting system plays an important role in each building, regardless of whether it is a natural or artificial source. In general, the most alluring light source is the normal light from sun alluded to as daylight. However, artificial sources of dimmable lighting are incandescent lamps, fluorescent lights (F-Lamps), light-emitting diode (LED), and compact fluorescent lights (CFLs). Dimmable Lamp has become a major method of lighting systems and have become widely used in the residential area [29]. Dimmers are devices used to lower the brightness of the light and connect to a light fixture. Therefore, this type of lamp is selected to be modelled in this study. The dimmer is modelled by getting the Simscape block (Simscape tool, 2017a) in Simulink that enables in short order to make physical frameworks. The physical tools from Simscape are represented as a dc voltage source, a resistor, a voltage sensor, a current sensor, an electric reference, and a solver configuration. The input of the Simulink blocks and the output of the Simscape blocks are connected through the PSSimulink converter that converts physical signals into Simulink signals. Also, the energy cost model is applied in the Simulink model of the dimmable three lamps used in this Simulink system. The dimmable lamp works according to the following values: $220 \mathrm{~V}, 15 \mathrm{~W}$, and the voltage source range $\left[V_{\min }=0, V_{\max }=120\right]$. It is worth mentioning that through changing the voltage waveform of the lamp, the light output intensity can be decreased and the lighting performance improved. The Simscape block diagram designed of the dimmable lamp is shown in Fig. 7.

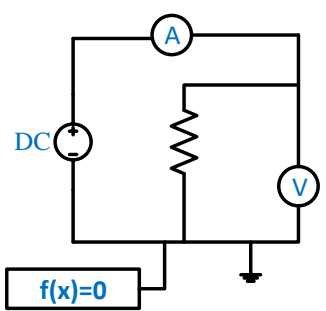

Fig. 7. Seascape model of the dimmable lamp. 


\section{FuZZY CONTROLleR SySTEM}

Fuzzy logic controllers (FLC) have been successfully developed and applied for system modelling in various fields [30]. In this study, after theoretical modelling based on the mathematical modelling utilizing equations that represent the three main domestic appliances using Simulink, the FLC is applied to achieve efficient energy management and cost reduction. The basic structure of the FLC system that developed in this study is shown in Fig. 8. It consists of four main components, including Fuzzier, Knowledgebase, Inference system, and Defuzzification. Fuzzier convert a crisp value (real value) signal into fuzzy sets distinguished by membership functions into a fuzzy set. The knowledge base represents the facts of the rules and linguistic variables. A fuzzy inference system assesses which control rules are important at present and afterwards chooses what the input to the plant oughts to be. At last, the defuzzification procedure changes over the fuzzy output into crisp value. The proposed FLC uses (11) to calculate the center of the area under the fuzzy membership functions in which $\mathrm{X}$ represents the center of the area

$$
X=\frac{\int(f(y) \times y) d y}{\int f(y) d y} .
$$

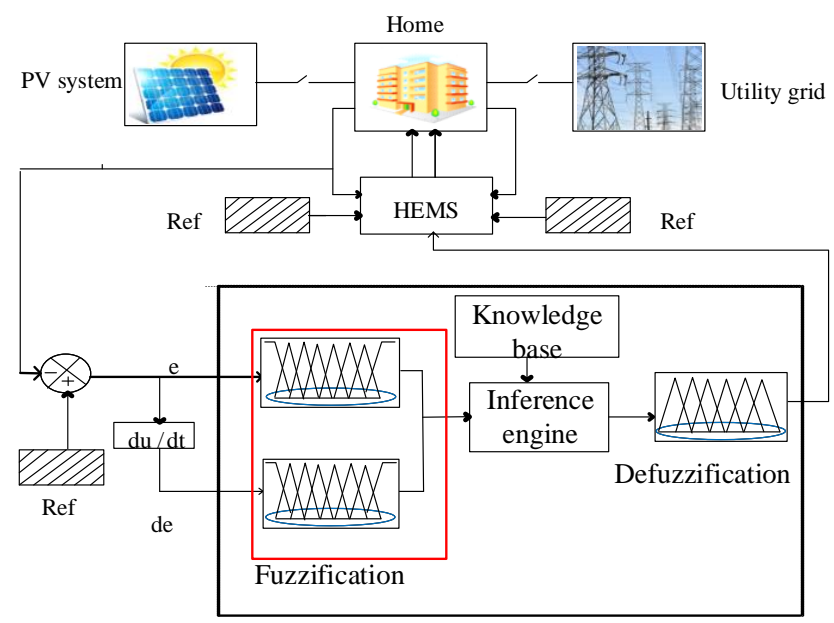

Fig. 8. The structure of FLC system applied for HEMS.

The most important aspect of fuzzy logic is the interpretation of membership functions for output and input data sets. For designing a model based on fuzzy logic, the best possible types and parameters for the membership features to suit the data set must be selected. There are different types of membership functions like triangular, sigmoidal, trapezoidal, Z-shaped, Gaussian, and S-shaped functions [31]. In the present work, we have used the Mamdani fuzzy (MF) inference system and Triangular membership function. Figure 9 shows of a Triangular membership function. In order to find the general variable of every fuzzy membership value (x), it can be calculated using the following triangular membership function equation

$$
\text { Triangle }(X ; \alpha, \beta, \gamma)=\left\{\begin{array}{cc}
0, & \text { if } \leq \alpha, \\
\frac{x-\alpha}{\gamma-\beta}, & \text { if } \alpha \leq x \leq \gamma, \\
\frac{\beta-x}{\beta-\gamma}, & \text { if } \gamma<x<\beta, \\
0, & \text { if } x \geq \beta .
\end{array}\right.
$$

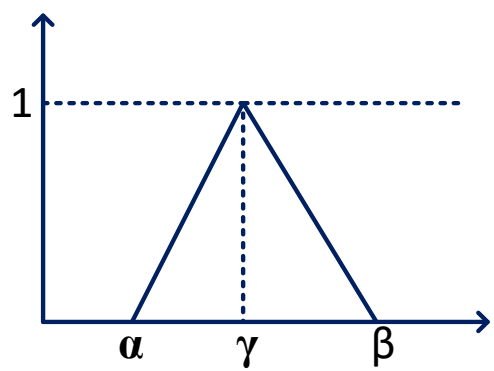

Fig. 9. Fuzzy triangular membership function.
A triangular $\mathrm{MF}$ is specified by three parameters $(\alpha, \beta, \gamma)$, in which $\alpha$ is a lower value, $\beta$ is an upper value, and $\gamma$ is the middle value.

\section{FUZZY BASED HEMS MODELS}

\section{A. Fuzzy Logic Controller for HVAC}

In this part, the role of FLC has been applied to model the HVAC systems. The FLC consists of two inputs and one output: the first one is an error and the second one is a change of error (the input error is derived and converted to the change of error input). In this system, the $\Delta T$ output is used as the variation between the HVAC indoor air temperature and the set-point temperature. For the fuzzy system of the HVAC control, nine membership functions were used: three per each input and output as illustrated in Fig. 10.

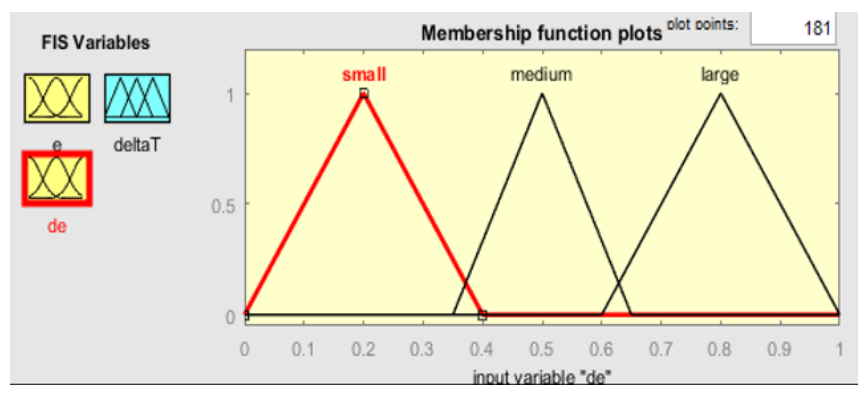

Fig. 10. Fuzzy membership function for second input (change of error).

The linguistic error variable is defined to have three fuzzy sets (very cool, medium cool, and large cool) with associated membership functions as left triangle, middle 
triangle, and right triangle, respectively. The fuzzy variable change of error is defined to have three fuzzy sets, which are small, medium, and large, with associated membership functions as left triangle, middle triangle, and right triangle, respectively. Besides, the fuzzy variable $\Delta T$ is defined to have three fuzzy sets (off, steady, and on) with associated membership functions as left triangle, middle triangle, and right triangle, respectively. The nine fuzzy rules are just used to measure the error and change of the output error as follows:

- If (e is very cool) and (de is small), then ( $\Delta T$ is on);

- If (e is very cool) and (de is medium), then ( $\Delta T$ is steady);

- If (e is very cool) and (de is large), then ( $\Delta T$ is off);

- If (e is medium cool) and (de is small), then $(\Delta T$ is on);

- If (e is medium cool) and (de is medium), then ( $\Delta T$ is steady);

- If (e is medium cool) and (de is large), then ( $\Delta T$ is off);

- If (e is large cool) and (de is small), then ( $\Delta T$ is on);

- If (e is large cool) and (de is medium), then ( $\Delta T$ is steady);

- If (e is large cool) and (de is large), then ( $\Delta T$ is off).

The fuzzy inference system's surface, which shows the $\Delta T$ changes with the variation of error and change of error, is shown in Fig. 11. If an error is cool while the change of error is small changes, then $\Delta T$ passing the heat temperature otherwise, the controller does not work. When the value of the error is 0.5 and the change of error is 0.5 too, then the value of $\Delta T$ is 2.25 as it is shown in Fig. 12. To show the behavior, the output steep amount against just one input error or change of error is illustrated in Fig. 13.

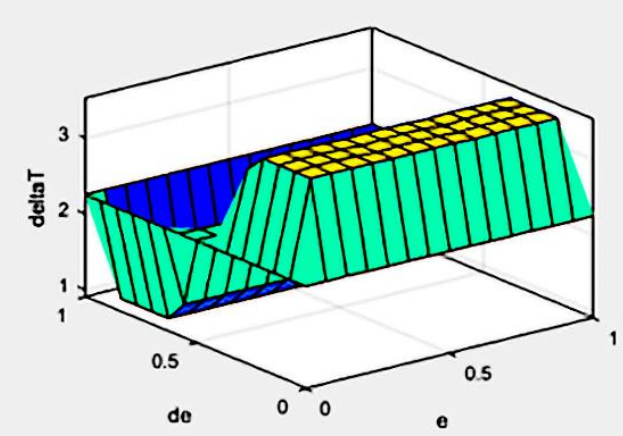

Fig. 11. A three-dimensional surface viewer of the fuzzy inference system.
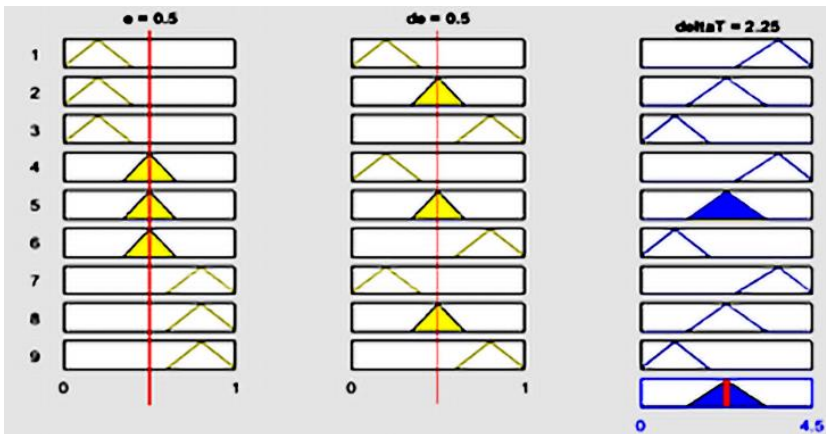

Fig. 12. Rules viewer of the fuzzy control system.

\section{A. Fuzzy Logic Controller for EWH}

In this study, two input variables and one output variable for the proposed fuzzy logic framework for the EWH model are developed.

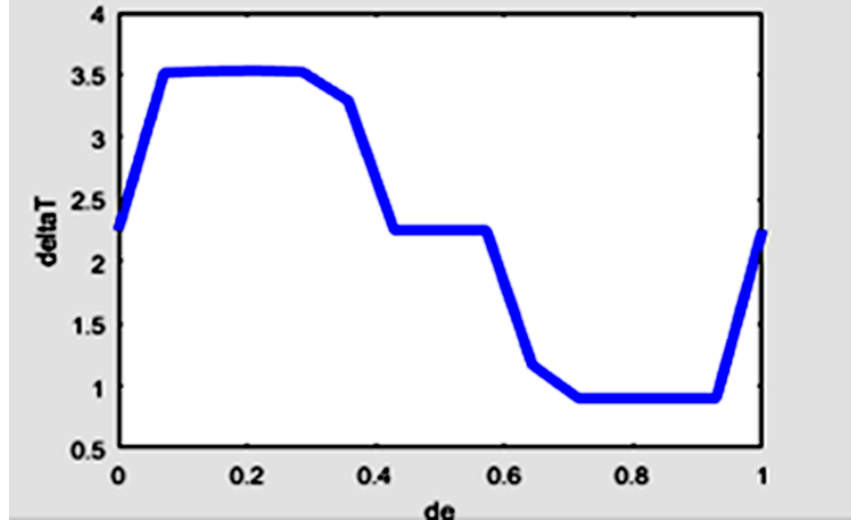

Fig. 13. Two-dimensional surface viewer of de versus delta operation.

The different types of input and output were divided into three fuzzy subsets. The linguistic system of the water heater controller overall used nine membership functions as shown in Fig. 14. Table I displays the rule-based FLC which is a set of if-then rules that maps inputs to outputs to control the EWH:

- Let $X=$ (low, medium, and high temperature) denote the error of the water heater. Each error is delineated by a membership function of a triangular form.

- Let $Y=$ (small, medium, and large) denote the change of error of the water heater. Each error is depicted by a membership function of a triangular form.

- Let $Z=$ (on, steady, and off) denote the power of the water heater. Each error is delimitated by a membership function of a triangular form.

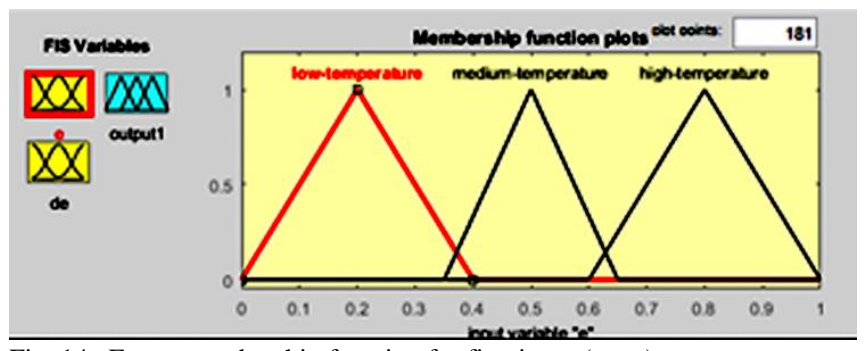

Fig. 14. Fuzzy membership function for first input (error).

\begin{tabular}{|c|c|c|c|}
\multicolumn{2}{|c|}{ TABLE I. THE RULE-BASED FUZZY LOGIC CONTROLLER. } \\
\hline \multirow{2}{*}{ Rules } & $\begin{array}{c}\text { IF } \\
\text { Error }\end{array}$ & $\begin{array}{c}\text { AND } \\
\text { Change of Error }\end{array}$ & $\begin{array}{c}\text { THEN } \\
\text { Power }\end{array}$ \\
\hline 1 & Low Temperature & Small & ON \\
\hline 2 & Low Temperature & Medium & Steady \\
\hline 3 & Low Temperature & Large & Off \\
\hline 4 & Medium Temperature & Small & ON \\
\hline 5 & Medium Temperature & Medium & Steady \\
\hline 6 & Medium Temperature & Large & Off \\
\hline 7 & High Temperature & Small & OFF \\
\hline 8 & High Temperature & Medium & Steady \\
\hline 9 & High Temperature & Large & ON \\
\hline
\end{tabular}

The fuzzy inference system (FIS) can map the given inputs to outputs using FLC. For instance, a typical mapping of a two-input, one-output fuzzy controller could be represented in a 3-D plot (control surface plot). In this regard, the control surface plot of the water heater (FIS) error, change of error, and power, respectively, is shown in Fig. 15. Figure 16 shows the fuzzy inference rules used to control the EWH using FLC. It can be seen that the first input value of the error $A_{1}=0.5$, the second input value of the change of error $A_{2}=0.5$, and the output decision of power $1.1 \mathrm{e}+0.3$. Figure 17 shows the surface viewer of $d e$ 
versus outputl operation.

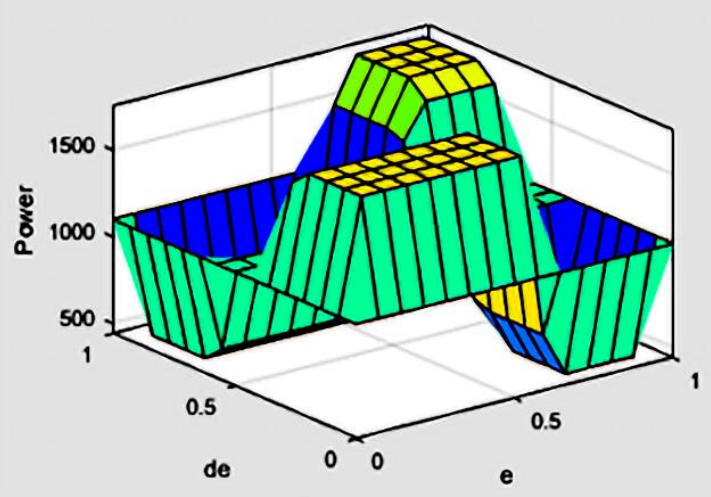

Fig. 15. The three-dimensional surface viewer of the fuzzy inference system.

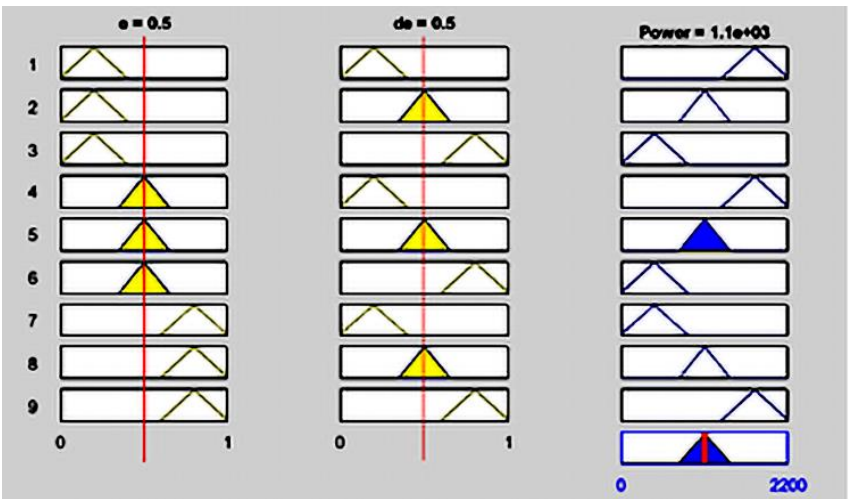

Fig. 16. Rules viewer of the fuzzy control system.

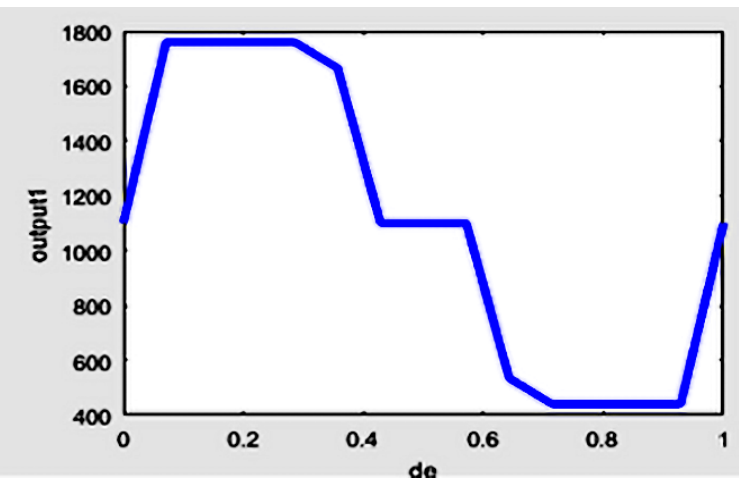

Fig. 17. The two-dimensional surface viewer of de versus output1 operation.

\section{B. Fuzzy Logic Controller for the Light}

The dimmable lamp model developed in this study has two inputs and one output linguistic variables. The input variables are represented from the voltage and current, however, the power is the output variable. In the proposed fuzzy system of the dimmable lamp control, nine membership functions were used: three per each input and output as illustrated in Fig. 18. The fuzzy variable current is defined to have three fuzzy sets (low, medium, and high) with associated membership functions as left triangle, middle triangle, and right triangle, respectively. In this design, the fuzzy variable voltage is defined to have three fuzzy sets (low, medium, and high) with associated membership functions as left triangle, middle triangle, and right triangle, respectively. On the other hand, the fuzzy variable power is defined to have three fuzzy sets (low, medium, and high) with associated membership functions as left triangle, middle triangle, and right triangle. The following nine fuzzy rules are used to calculate the voltage and current output. It is worth noting that the controller incorporated nine inference rules that conclude to four IFTHEN rules, as mentioned above, in which the "IF" part is called "antecedent" and "THEN" part is called "consequent".

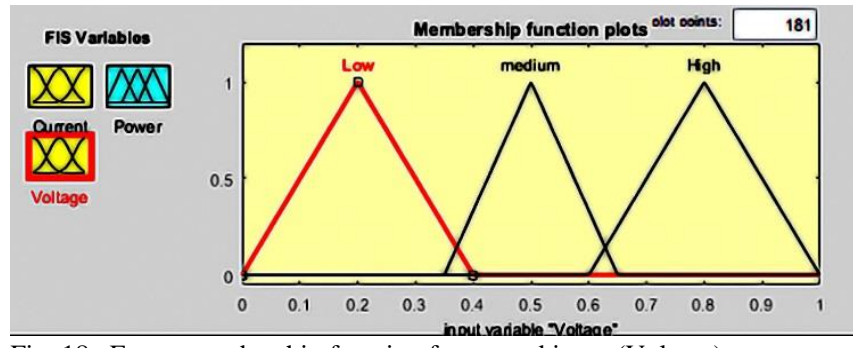

Fig. 18. Fuzzy membership function for second input (Voltage).

TABLE II. THE RULE-BASED FUZZY LOGIC CONTROLLER

\begin{tabular}{|c|c|c|c|}
\hline $\begin{array}{c}\text { Koltage } \\
\text { Current }\end{array}$ & LOW & MEDIUM & HIGH \\
\hline LOW & Low & Low & Low \\
\hline LOW & Low & Medium & Medium \\
\hline LOW & Low & Medium & Medium \\
\hline
\end{tabular}

The surface of the fuzzy inference process (control surface plot of the light), which illustrates the power changes with the variation of voltage and current, is shown in Fig. 19. Figure 20 shows the fuzzy inference rules used for the Light model using FLC. It can be seen, that when the value of the voltage is 0.5 and the current is 0.5 too, the value of power is 10 . In addition, Fig. 21 shows the surface viewer of power control using the voltage.

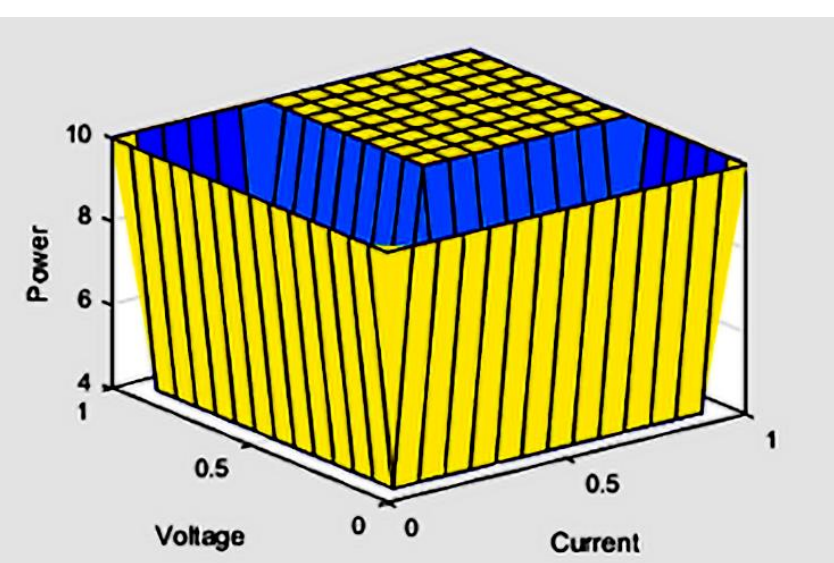

Fig. 19. A three-dimensional surface viewer of the fuzzy inference system
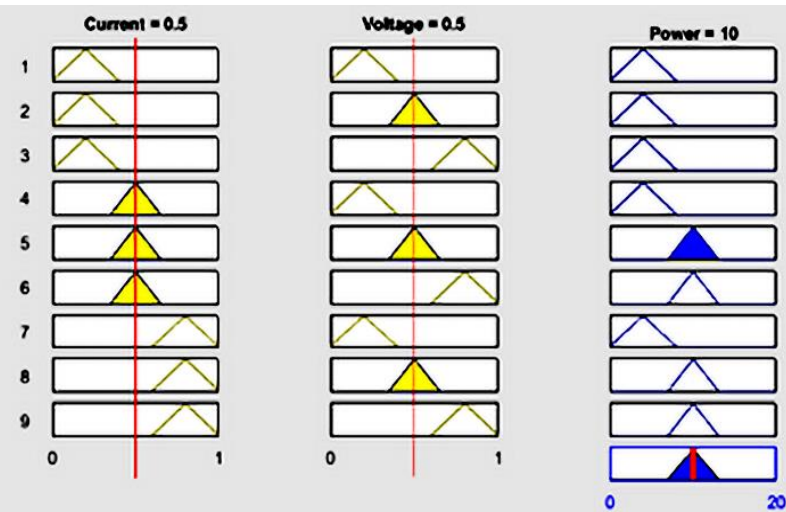

Fig. 20. Rules viewer of the fuzzy control system. 


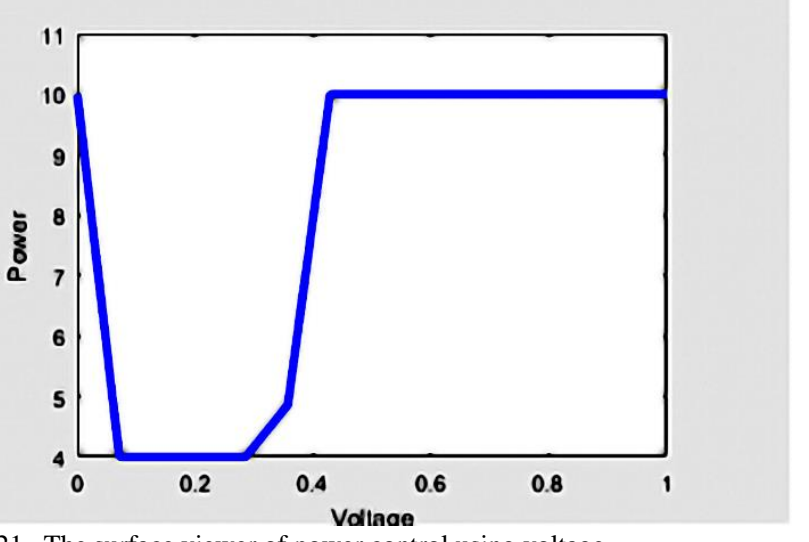

Fig. 21. The surface viewer of power control using voltage.

\section{RESUltS ANALYSIS}

The modelling in this study is conducted to manage the energy of the three domestic appliances, including the HVAC, water heating, and lighting, as a case study in Malaysia. The modelling is developed based on mathematical equations that represent these appliances using the Matlab/Simulink environment. Next, a FLC is applied for energy management and cost reduction purposes. Based on the Malaysian national electrical company (TNB), the tariff for domestic use at peak hours (08:00-22:00) is $0.365 \mathrm{RM}$, and for off-peak hours (22:00-08:00) 0.224 RM. Therefore, these values are considered as a reference in this study. It is important to mention that the minimum charge per month is $6 \mathrm{RM}$, where one $\mathrm{RM}$ is equivalent to around $0.24 \$$. For the HVAC system, there is no consumption of power during the period from 00:00 am to 20:00 pm. Therefore, the total energy cost is zero. The time determined to use the heating ventilation air conditioning (HVAC) is from 20:00 to 23:00. Therefore, based on the model shown in Fig. 2 and (1)-(6), the power consumption without a controller is around $2 \mathrm{~kW}$. However, after using the FLC, it can be noticed that the power consumption is decreased to around $1.5 \mathrm{~kW}$. As a result, based on the cost model developed and the electricity tariff, the rate of electricity cost without FLC is $1.855 \mathrm{RM}$. However, when the FLC is applied, the cost of energy for the HVAC system is decreased to $1.491 \mathrm{RM}$, which is $21.75 \%$ as shown in Fig. 22. In addition, it can be seen that the reduction in power consumed using the proposed FLC and consequently reduction in the cost indicate the effectiveness of the FLC. Based on the analysis above, a comparative analysis among the algorithm techniques has been explained in Table III.

TABLE III. COMPARISON TO THE ACCURACY COMPLEXITY AND PERFORMANCE OF THE PROPOSED ALGORITHM.

\begin{tabular}{|c|c|c|c|c|}
\hline $\begin{array}{l}\text { Algorithm } \\
\text { Technique }\end{array}$ & Complexity & Accuracy & Performance & Ref. \\
\hline ANN & $\begin{array}{l}\text { Complex design } \\
\text { and implementation }\end{array}$ & $\begin{array}{l}\text { Although the accuracy } \\
\text { of ANN differ from } \\
\text { application to another, } \\
\text { for HEM, its accuracy } \\
\text { reached to } 91.19 \%\end{array}$ & $\begin{array}{l}\text { It can achieve good performance if appropriate activation } \\
\text { functions, training data, and several nodes are selected. The } \\
\text { home appliances are reduced less power consumption and energy } \\
\text { cost. This method decreased the energy consumption } 3.0832 \% \text {. }\end{array}$ & $\begin{array}{l}\text { Maytham S. } \\
\text { Ahmed } \text { et al. } \\
\text { [32], } \\
\text { Balachander, K. } \\
\quad \text { et al. } \text { [33] }\end{array}$ \\
\hline ANFIS & $\begin{array}{l}\text { Averagely complex } \\
\text { of design and } \\
\text { implementation }\end{array}$ & $99.976 \%$ & $\begin{array}{l}\text { It can achieve good performance if suitable training data and } \\
\text { type of membership function are selected. This approch reduces } \\
\text { energy consumption from } 9.7 \% \text { to } 25 \% \text {. }\end{array}$ & $\begin{array}{l}\text { Zahra Pezeshki } \\
\text { et al. [34], } \\
\text { Hussain } \\
\text { Khashif } \text { et al. } \\
\quad \text { [35] }\end{array}$ \\
\hline PID & $\begin{array}{l}\text { Moderate } \\
\text { calculation and } \\
\text { implementation }\end{array}$ & - & $\begin{array}{l}\text { It can achieve good performance if the PID controller } \\
\text { continuously calculates an error value as the difference between } \\
\text { the desired set-point and measured process variable and applies a } \\
\text { correction based on proportional integral and derivative terms. } \\
\text { This method decreased the energy consumption } 22 \% \text {. }\end{array}$ & $\begin{array}{l}\text { S. E. Diaz- } \\
\text { Mendez et al. } \\
\quad[36]\end{array}$ \\
\hline
\end{tabular}

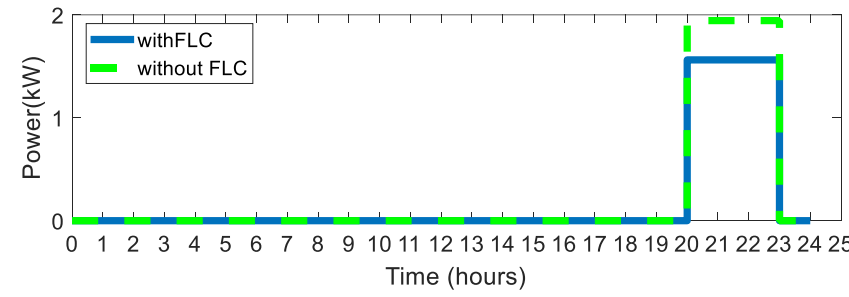

(a)

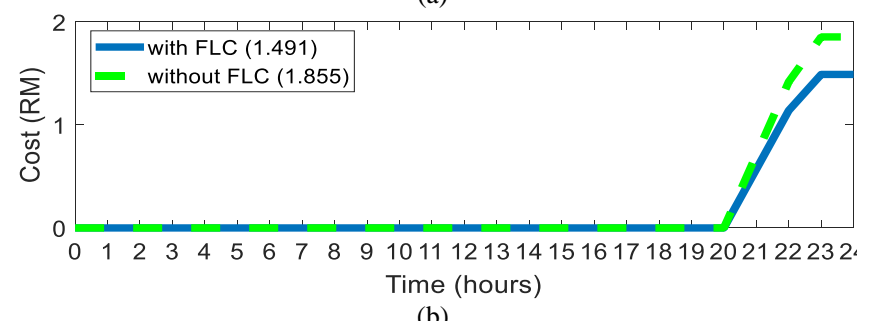

(b)

Fig. 22. With and without FLC controller for the HVAC system: (a) power consumption and (b) energy cost.
In terms of electric water heater, the results of the model developed in Fig. 6 show that when the water heater is used at two periods, from 08:00 am to 09:00 am and from 14:00 pm to $15: 00 \mathrm{pm}$, the energy consumption is $1.5 \mathrm{~kW}$. However, when the FLC is applied, the power consumption decreased into around $1 \mathrm{~kW}$. For the two operation periods of EWH that considered as peak hour (based on the power company tariff), the electricity price is $0.54 \mathrm{RM}$ for each; therefore, the cost in the second period is raised to $1.09 \mathrm{RM}$. On the other hand, once the FLC is applied to manage the power consumption and energy cost, the cost is reduced to $0.803 \mathrm{RM}$ for the two periods of operation. Figure 23 shows the power consumption and cost of EWH with and without using FLC. Figure 24 shows the power consumption of light during two periods. The first one is from 07:00 am to 08:00 am and the second one - from 6:30 pm to 12:00 am. It can be noticed that the power consumption without and with 
FLC is around $0.35 \mathrm{~kW}$ and $0.5 \mathrm{~kW}$, respectively. Therefore, the cost is reduced from $0.086 \mathrm{RM}$ to $0.0578 \mathrm{RM}$ without and with FLC, which is $41.96 \%$. In sum, the results demonstrated that the FLC could help in HEMS to minimize the power consumption, and thus reduce the electricity bill.

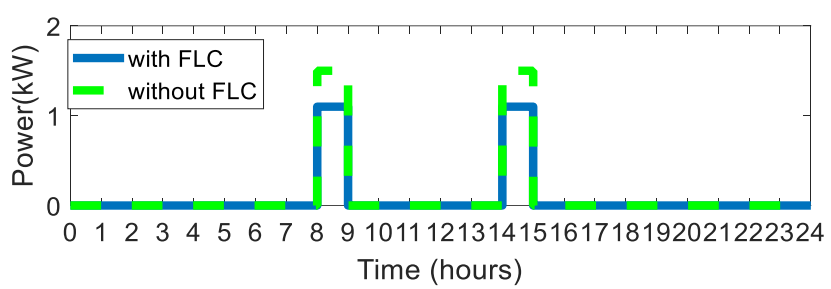

(a)

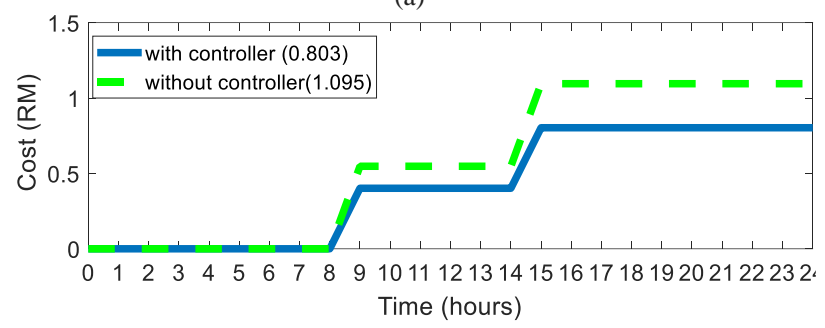

(b)

Fig. 23. With and without FLC controller for EWH system: (a) power consumption and (b) energy cost.

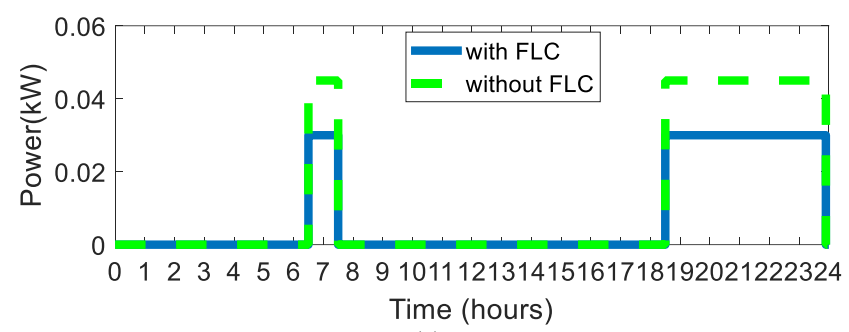

(a)

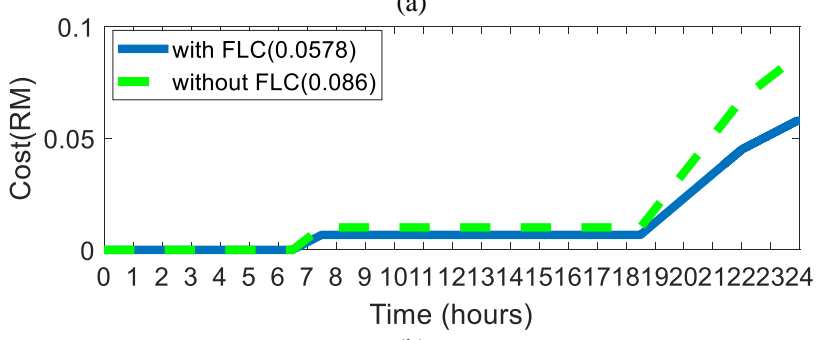

(b)

Fig. 24. With and without FLC controller for light system: (a) power consumption and (b) energy cost.

\section{CONCLUSIONS}

Energy management in the home sector is considered as one of the key solutions with regard to climate change targets and energy crises. In this study, the consumption of energy of most domestic household appliances is modelled and analysed using Simulink/Matlab. In addition, FLC is developed in order to permit the home energy management system to perform energy utilization estimation and cost analysis of various sorts of appliances. The designed simulator can help to analyse their energy consumption and cost sceneries during peak and off-peak hours. These appliances are the HVAC, water heating, and lighting. The development of a domestic household appliances model for home energy management systems in Malaysia based on the national grid tariff is analysed. The results of this study proved that the power consumption reduced from $2 \mathrm{~kW}$, $1.5 \mathrm{~kW}$, and $0.5 \mathrm{~kW}$ for the HVAC, EWH, and dimmable lamps without FLC to $1.5 \mathrm{~kW}, 1 \mathrm{~kW}$, and $0.35 \mathrm{~kW}$ with FLC, respectively. Therefore, the cost of energy is reduced by $21.75 \%, 30.77 \%$, and $41.96 \%$ using FLC for the HVAC, EWH, and dimmable lamps, respectively. In sum, the FLC shows good performance to reduce the cost and power consumption toward efficient HEMS. It is suggested to apply some optimization algorithm, such as Particle Swarm Optimization (PSO), Genetic Algorithm (GA), Backtracking Search Algorithm (BSA), etc., to optimize home appliances for cost and consumption reduction purposes. Moreover, a hybrid technique between controllers and optimization techniques, such as fuzzy logic controller (FLC)-PSO, can be applied to ensure better performance compared to the system that contains controller only.

\section{CONFLICTS OF INTEREST}

The authors declare that they have no conflicts of interest.

\section{REFERENCES}

[1] M. S. Ahmed, A. Mohamed, R. Z. Homod, and H. Shareef, "Hybrid LSA-ANN based home energy management scheduling controller for residential demand response strategy", Energies, vol. 9, no. 9, p. 716, 2016. DOI: $10.3390 /$ en9090716.

[2] A. Atmaca, "Life cycle assessment and cost analysis of residential buildings in south east of Turkey: part 1-review and methodology", The International Journal of Life Cycle Assessment, vol. 21, pp. 831846, 2016. DOI: 10.1007/s11367-016-1050-8.

[3] H. Shareef, M. S. Ahmed, A. Mohamed, and E. Al Hassan, "Review on home energy management system considering demand responses, smart technologies, and intelligent controllers", IEEE Access, vol. 6 , pp. 24498-24509, 2018. DOI: 10.1109/ACCESS.2018.2831917.

[4] S. Aman, Y. Simmhan, and V. K. Prasanna, "Energy management systems: State of the art and emerging trends", IEEE Communications Magazine, vol. 51, no. 1, pp. 114-119, 2013. DOI: 10.1109/MCOM.2013.6400447.

[5] A. Q. Al-Shetwi, M. A. Hannan, K. P. Jern, M. Mansur, and T. M. I. Mahlia, "Grid-connected renewable energy sources: Review of the recent integration requirements and control methods", Journal of Cleaner Production, vol. 253, p. 119831, 2020. DOI: 10.1016/j.jclepro.2019.119831.

[6] S. S. Hosseini, K. Agbossou, S. Kelouwani, and A. Cardenas, "Nonintrusive load monitoring through home energy management systems: A comprehensive review", Renewable and Sustainable Energy Reviews, vol. 79, pp. 1266-1274, 2017. DOI 10.1016/j.rser.2017.05.096.

[7] I. Richardson, M. Thomson, D. Infield, and C. Clifford, "Domestic electricity use: A high-resolution energy demand model", Energy and Buildings, vol. 42, no. 10, pp. 1878-1887, 2010. DOI: 101016/j.enbuild.2010.05.023.

[8] H. Li, Ch. Zang, P. Zeng, H. Yu, Zh. Li, and N. Fenglian, "Optimal home energy management integrating random PV and appliances based on stochastic programming", in Proc. of 2016 Chinese Control and Decision Conference (CCDC), 2016, pp. 429-434. DOI: 10.1109/CCD.2016.7531023.

[9] M. Pipattanasomporn, M. Kuzlu, and S. Rahman, "An algorithm for intelligent home energy management and demand response analysis", IEEE Transactions on Smart Grid, vol. 3, no. 4, pp. 2166-2173, 2012. DOI: 10.1109/TSG.2012.2201182.

[10] Z. Wu, S. Zhou, J. Li, and X.-P. Zhang, "Real-time scheduling of residential appliances via conditional risk-at-value", IEEE Transactions on Smart Grid, vol. 5, no. 3, pp. 1282-1291, 2014. DOI: 10.1109/TSG.2014.2304961.

[11] C. Chen, J. Wang, Y. Heo, and S. Kishore, "MPC-based appliance scheduling for residential building energy management controller", IEEE Transactions on Smart Grid, vol. 4, no. 3, pp. 1401-1410, 2013. DOI: 10.1109/TSG.2013.2265239.

[12] H. Nagpal, A. Staino, and B. Basu, "Automated scheduling of household appliances using predictive mixed integer programming", Preprints, 2019. DOI: 10.20944/preprints201902.0256.v1.

[13] R. Yang and L. Wang, "Multi-zone building energy management using intelligent control and optimization", Sustainable cities and society, vol. 6, pp. 16-21, 2013. DOI: 10.1016/j.scs.2012.07.001.

[14] Y. Zhang, Y. Zhong, Y. Gong, and L. Zheng, "The optimization of 
visual comfort and energy consumption induced by natural light based on PSO", Sustainability, vol. 11, no. 1, p. 49, 2019. DOI: 10.3390/su11010049.

[15] D. Zhang, S. Li, M. Sun, and Z. O’Neill, “An optimal and learningbased demand response and home energy management system", IEEE Transactions on Smart Grid, vol. 7, no. 4, pp. 1790-1801, 2016. DOI: 10.1109/TSG.2016.2552169.

[16] K. Parvin, M. A. Hannan, A. Q. Al-Shetwi, P. J. Ker, M. F. Roslan, and T. M. I. Mahlia, "Fuzzy based Particle Swarm Optimization for modeling home appliances towards energy saving and cost reduction under demand response consideration", IEEE Access, vol. 8, pp. 210784-210799, 2020. DOI: 10.1109/ACCESS.2020.3039965.

[17] M. Faisal, M. A. Hannan, P. J. Ker, A. Hussain, M. B. Mansor, and F. Blaabjerg, "Review of energy storage system technologies in microgrid applications: Issues and challenges", IEEE Access, vol. 6 , pp. 35143-35164, 2018. DOI: 10.1109/ACCESS.2018.2841407.

[18] Y.-Y. Hong, J.-K. Lin, Ch.-P. Wu, and Ch.-Ch. Chuang, "Multiobjective air-conditioning control considering fuzzy parameters using immune clonal selection programming", IEEE Transactions on Smart Grid, vol. 3, no. 4, pp. 1603-1610, 2012. DOI: 10.1109/TSG.2012.2210059.

[19] A. Mohsenzadeh, M. H. Shariatkhah, and M.-R. Haghifam, “Applying fuzzy techniques to model customer comfort in a smart home control system", in Proc. of 22nd International Conference and Exhibition on Electricity Distribution (CIRED 2013), 2013, pp. 1-4. DOI: 10.1049/cp.2013.1100.

[20] L. Ciabattoni, M. Grisostomi, G. Ippoliti, and S. Longhi, "Home energy management benefits evaluation through fuzzy logic consumptions simulator", in Proc. of 2014 International Joint Conference on Neural Networks (IJCNN), 2014, pp. 1447-1452. DOI: 10.1109/IJCNN.2014.6889855.

[21] N. Rajeswari and J. Janet, "Load scheduling using fuzzy logic in a home energy management system", vol. 10, no. 5, pp. 1263-1272, 2018. DOI: $10.21817 / \mathrm{ijet} / 2018 / \mathrm{v} 10 \mathrm{i} 5 / 181005013$.

[22] E. Fuentes, L. Arce, and J. Salom, “A review of domestic hot water consumption profiles for application in systems and buildings energy performance analysis", Renewable and Sustainable Energy Reviews, vol. 81, part I, pp. 1530-1547, 2018. DOI: 10.1016/j.rser.2017.05.229.

[23] M. Killian, B. Mayer, and M. Kozek, "Cooperative fuzzy model predictive control for heating and cooling of buildings", Energy Build., vol. 112, pp. 130-140, Jan. 2016. DOI: 10.1016/J.ENBUILD.2015.12.017.

[24] M. Killian and M. Kozek, "Implementation of cooperative fuzzy model predictive control for an energy-efficient office building", Energy Build., vol. 158, pp. 1404-1416, Jan. 2018. DOI: 10.1016/J.ENBUILD.2017.11.021.

[25] Y. Ma, P. Duan, Y. Sun, and H. Chen, "Equalization of lithium-ion battery pack based on fuzzy logic control in electric vehicle", IEEE Trans. Ind. Electron., vol. 65, no. 8, pp. 6762-6771, Aug. 2018. DOI: 10.1109/TIE.2018.2795578.

[26] M. A. Hannan, Z. ABD. Ghani, Md. M. Hoque, P. J. Ker, A. Hussain, and A. Mohamed, "Fuzzy logic inverter controller in photovoltaic applications: Issues and recommendations", IEEE Access, vol. 7, pp. 24934-24955, 2019. DOI: 10.1109/ACCESS.2019.2899610.

[27] R. Khalid, N. Javaid, M. H. Rahim, Sh. Aslam, and A. Sher, "Fuzzy energy management controller and scheduler for smart homes", Sustain. Comput. Informatics Syst., vol. 21, pp. 103-118, 2019. DOI: 10.1016/j.suscom.2018.11.010

[28] S. Bissey, S. Jacques, and J.-Ch. Le Bunetel, "The fuzzy logic method to efficiently optimize electricity consumption in individual housing", Energies, vol. 10, no. 11, p. 1701, 2017. DOI: 10.3390/en10111701.

[29] M. A. Z. Alvarez, K. Agbossou, A. Cardenas, S. Kelouwani, and L. Boulon, "Demand response strategy applied to residential electric water heaters using dynamic programming and k-means clustering", IEEE Transactions on Sustainable Energy, vol. 11, no. 1, pp. 524 533, 2020. DOI: 10.1109/TSTE.2019.2897288.

[30] D. Andriukaitis, A. Laucka, A. Valinevicius, M. Zilys, V. Markevicius, D. Navikas, R. Sotner, J. Petrzela, J. Jerabek, N Herencsar, and D. Klimenta, "Research of the Operator's Advisory System Based on Fuzzy Logic for Pelletizing Equipment”, Symmetry, vol. 11, no. 11, p. 1396, Nov. 2019 DOI: 10.3390/sym11111396.

[31] M. Dudzik, M. Dechnik, and M. Furtak, "Application of neural networks to lighting systems", in Proc. of MATEC Web of Conferences, 2019, vol. 282, p. 02069. DOI: 10.1051/matecconf/2019282069.

[32] M. S. Ahmed, A. Mohamed, H. Shareef, R. Z. Homod, and J. A. Ali, "Artificial neural network based controller for home energy management considering demand response events", in Proc. of 2016 Int. Conf. Adv. Electr. Electron. Syst. Eng. ICAEES 2016, 2016, pp. 506-509. DOI: 10.1109/ICAEES.2016.7888097.

[33] K. Balachander and D. Paulraj, "ANN and fuzzy based household energy consumption prediction with high accuracy", Journal of Ambient Intelligence and Humanized Computing, pp. 1-15, 2020. DOI: $10.1007 / \mathrm{s} 12652-020-02455-4$.

[34] Z. Pezeshki, S. M. Mazinani, and E. Omidvar, "Outdoor temperature estimation using ANFIS for soft sensors", J. Auton. Intell., vol. 2, no. 3, pp. 19-29, 2019. DOI: 10.32629/jai.v2i3.58.

[35] K. Hussain and Mohd. N. Mohd. Salleh, "Analysis of techniques for ANFIS rule-base minimization and accuracy maximization", ARPN Journal of Engineering and Applied Sciences, vol. 10, no. 20, pp 9739-9746, 2015.

[36] S. E. Diaz-Mendez, C. Patiño-Carachure, and J. A. Herrera-Castillo, "Reducing the energy consumption of an earth-air heat exchanger with a PID control system", Energy Convers. Manag., vol. 77, pp. 16, Jan. 2014. DOI: 10.1016/J.ENCONMAN.2013.09.033

This article is an open access article distributed under the terms and conditions of the Creative Commons Attribution 4.0 (CC BY 4.0) license (http://creativecommons.org/licenses/by/4.0/). 